\title{
BMJ Open Comparing socially disadvantaged smokers who agree and decline to participate in a randomised smoking cessation trial
}

Billie Bonevski, ${ }^{1}$ Laura Twyman, ${ }^{1}$ Chris Paul, ${ }^{2}$ Catherine D'Este, ${ }^{3}$ Robert West, ${ }^{4}$ Mohammad Siahpush, ${ }^{5}$ Christopher Oldmeadow, ${ }^{6}$ Kerrin Palazzi, ${ }^{6}$ Jamie Bryant, ${ }^{2}$ Ashleigh Guillaumier ${ }^{1}$

To cite: Bonevski $\mathrm{B}$, Twyman L, Paul C, et al. Comparing socially disadvantaged smokers who agree and decline to participate in a randomised smoking cessation trial. BMJ Open 2015;5:e008419. doi:10.1136/bmjopen-2015008419

- Prepublication history for this paper is available online. To view these files please visit the journal online (http://dx.doi.org/10.1136/ bmjopen-2015-008419).

Received 8 April 2015 Revised 13 August 2015 Accepted 14 August 2015

CrossMark

For numbered affiliations see end of article.

\section{Correspondence to} Professor Billie Bonevski; billie.bonevski@newcastle. edu.au

\section{ABSTRACT}

Objectives: This study examined sociodemographic, smoking and psychosocial characteristics associated with consent to participate in a smoking cessation trial for socially disadvantaged smokers.

Design: Baseline data were collected prior to seeking consent for the Call it Quits, a randomised controlled trial.

Setting: An Australian social and community service organisation. Sociodemographic, smoking and psychosocial characteristics were compared between smokers who agreed or declined to participate.

Participants: Of the 584 smokers invited to participate, 431 (74\%) consented and $153(26 \%)$ declined.

Results: Logistic regression modelling indicates the ORs of participation were twice as high for those reporting 'high' motivation to quit compared to the 'moderate' motivation group, and five times higher than the 'low' motivation group $(p=0.007)$. The $0 R$ s of consenting were higher for those with a preference for gradual reduction in cigarettes in quit attempts compared with 'no preference'. The ORs were lower for those reporting 'don't know' regarding their enjoyment of smoking compared to 'not at all' enjoying smoking, and reporting that fewer of their family or friends smoked compared to 'most or all'.

Conclusions: This study is the first to examine the characteristics of socially disadvantaged smokers who consent or decline to participate in a smoking cessation trial. Low-income smokers who are motivated to quit, are not enjoying smoking, had family or friends who smoked, and who are interested in gradual cessation approaches may be more likely to participate in a smoking cessation trial.

Trial registration number: ISRCTN85202510.

\section{INTRODUCTION}

Smoking cessation for socially disadvantaged groups is a public health priority in most developed countries due to the

\section{Strengths and limitations of this study}

- This is the first study to look at which disadvantaged individuals are more likely to participate in a smoking cessation trial, reporting the demographics of individuals less likely to consent to participate in a smoking cessation trial.

- We identified that low-income smokers who are motivated to quit, are not enjoying smoking, had family or friends who smoked, and are interested in gradual cessation approaches may be more likely to participate in a smoking cessation trial.

- A limitation of this paper is that it utilises a two-step recruitment process which, while useful in providing depth and breadth of information about trial participants and non-participants, excludes eligible individuals who were not interested or did not consent into the initial health survey.

- A further study limitation is that external factors not explored in this study, such as lack of time, a high crisis situation for visiting the nongovernment social and community service organisation, and low literacy levels, may also contribute to non-participation.

disproportionate disease burden attributable to tobacco smoking among these groups. ${ }^{12}$ However, smoking cessation trials which have attempted to target members of socially disadvantaged groups have usually achieved only small sample sizes and low consent rates. ${ }^{3}$ Trials that draw samples from the general population are rarely powered to adequately examine outcomes according to social group. ${ }^{3}$ As a result, knowledge of effective ways to improve smoking cessation among socially disadvantaged groups is lacking.

Generally in health and medical research, groups from socioeconomically lower status have been under-represented. A recent comprehensive systematic review of the barriers 
to participation in medical research for disadvantaged groups were numerous, including difficulties in identifying and sampling the hidden populations, mistrust of medical research and researcher, cultural or language barriers, low literacy, and low education levels. ${ }^{3}$

To improve consent rates for trials targeting samples from socially disadvantaged groups, it is important to gain an understanding of the characteristics of individuals who are likely to consent to participate in trials and those who are less able or willing to participate. This information can help inform the development of recruitment strategies for smoking cessation trials.

Few studies have compared the characteristics of smoking cessation trial participants to non-participants with smokers from socially disadvantaged groups. ${ }^{45}$ In the USA, Warner et at described the factors associated with eligible consenting smokers recruited from homelessness shelters returning for a randomisation appointment. The authors found that those who returned were older and more likely to have a phone contact than eligible participants who failed to return. This study is limited, however, in that it only compared a small number of factors affecting participation, and no data were available on those smokers who declined participation at the consent stage.

This paper will describe consent rates for a sample of socially disadvantaged smokers who were approached to participate in an Australian trial-Call it Quits (CiQ) - to increase cessation among a socially disadvantaged group of smokers. ${ }^{6}$ In order to obtain a large sample of smokers who experience high levels of multiple forms of disadvantage including homelessness, unemployment, mental illness, substance abuse, and Indigenous status, recruitment took place within a non-government social and community service organisation (SCSO). These services provide a range of counselling, material (food and financial), and emergency welfare aid to people in need across Australia. Previous research has shown that smoking prevalence is between $60 \%$ and $70 \%$ among the adult clients of SCSOs. ${ }^{7}$ A number of evidence-based strategies were used to increase response rates for the trial, ${ }^{3}$ including the offer of smoking cessation support at no cost which included an offer of free nicotine replacement therapy (NRT), financial reimbursement for time spent completing the trial surveys, the use of simple, low reading age study materials, and use of an engaging and acceptable computerised health survey. ${ }^{3} 8$

The current study will examine the sociodemographic, smoking, alcohol use and psychosocial characteristics associated with consent to participate in the CiQ trial. Data for this study were collected during a baseline survey which was administered prior to seeking consent for the trial, enabling participant and non-participant characteristics to be compared. This provides new and unique information on the differences between smokers from socially disadvantaged groups who agree or decline consent to participate in a smoking cessation trial.

\section{METHODS}

\section{Study design}

A self-administered cross-sectional survey was conducted to assess eligibility for inclusion in a trial, to collect health-related data, and to collect baseline trial data. The CiQ trial, which has been described in detail elsewhere ${ }^{6}$ is a randomised controlled trial of a five-session SCSO case-worker delivered smoking cessation intervention for socially disadvantaged smokers.

\section{Setting and sample}

Study participants were recruited from a large SCSO in regional NSW, Australia. Participants eligible for inclusion in the baseline cross-sectional survey were SCSO clients who were aged 18 years and above, sufficiently fluent in English, and well enough on the day of recruitment to give informed consent and complete a survey. SCSO clients who presented as agitated, distressed or under the influence of alcohol or other drugs were ineligible to participate. Individuals from socially disadvantaged groups are expected clients of these services, including those who are Aboriginal Australians, unemployed and living on government welfare, homeless, with a mental illness or drug addiction, and young single parents. ${ }^{9}$ Most SCSO clients report multiple forms of disadvantage.

\section{Procedures}

A two-stage consent process was used where clients were asked to: (1) consent to complete a general health survey, and if they completed the survey and were identified as eligible; (2) were asked to consent to participate in a smoking cessation trial. Initially, all clients who presented for their SCSO appointment were informed by staff that the service was involved in a university health survey. SCSO staff asked eligible clients interested in participating to present to the Research Assistant (RA) who reassessed eligibility, provided the client with a participant information statement and sought written consent to participate in a health survey. Those clients who completed the computer-administered health survey and were identified during the survey as current tobacco smokers, viewed a final survey screen inviting participation in further research where they may receive a service-based smoking cessation programme. The RA provided willing clients with the $\mathrm{CiQ}$ trial participant information statement and sought written consent for participation in the trial.

All participants who completed the health survey received a $\$ 20$ grocery voucher, regardless of whether or not they enrolled into the CiQ trial. During recruitment, those participants who were eligible for the trial were advised that they would receive a further $\$ 50$ voucher at each follow-up data collection period (1 and 6 months). All study procedures were approved by the University of Newcastle's Human Research Ethics Committee (H-2010-1002). 


\section{Survey instrument}

A 62-item computer survey was administered using Digivey survey software. ${ }^{10}$ To assess eligibility for inclusion in the smoking cessation trial, the following two items were used to determine smoking status: (1) "Do you currently smoke tobacco products?", with the following response options (A) "Yes, daily" (B) "Yes, at least once a week" (C) "Yes, but less often than once a week" and (D) "No, not at all" and; (2) "Have you smoked at least 100 cigarettes or a similar amount of tobacco in your life?" with response options (A) 'Yes' (B) 'No' (C) 'Not sure'. Current smokers were defined as self-reported daily or occasional smokers who had smoked at least 100 cigarettes in their lifetime. Only those participants who identified as current smokers were invited to participate in this study.

Lifetime quit attempts were assessed by asking all participants, "Have you ever tried to quit smoking before (Yes/ No)?"11

Abrupt versus gradual cessation preference: Participants were asked, "If you were thinking of quitting smoking, would you prefer to stop suddenly or gradually cut down on the number of cigarettes you smoke?" Response options were (1) stop smoking suddenly, (2) gradually cut down the number of cigarettes I smoked or (3) I would not have a preference. ${ }^{12}$

Intentions to quit were assessed using the following questions: "What are your intentions regarding quitting? Do you plan to: (1) Quit in the next 30 days, (2) Quit in the next 6 months, (3) Quit, but not in the next 6 months, (4) Never quit, or (5) Don't know."

Self-efficacy was assessed by asking: "If you decided to give up smoking completely in the next 6 months, how sure are you that you would succeed?" Response options were: (1) not at all sure, (2) slightly sure, (3) moderately sure, (4) very sure or (5) extremely sure. ${ }^{11}$

Enjoyment of smoking was assessed by asking: "How much do you enjoy smoking?" Response options were: (1) very much, (2) quite a bit, (3) not particularly, (4) not at all or (5) do not know. ${ }^{13}$

Smoker identity was assessed by asking: "Which of these statements most applies to you?" Response options were: (1) I hate being a smoker, (2) I am unhappy about being a smoker, (3) I am happy about being a smoker, or (4) do not know. ${ }^{14}$

Motivation to quit was measured on a 10-point Likert scale: "On a scale of one to ten, please rate your current motivation to give up smoking" ( $1=$ very low motivation, $10=$ very high motivation). Responses were collapsed into the following categories: $1-3=$ low motivation, $4-6=\bmod -$ erate motivation, and $7-10=$ high motivation and used as a categorical measure. ${ }^{15}$

Nicotine dependence was measured using the two-item Heaviness of Smoking Index (HSI). ${ }^{16}$ The Heaviness of Smoking Index uses time after waking to first cigarette and number of cigarettes smoked per day to form an index from zero to six, with higher scores indicating higher levels of nicotine dependence $(0-2=$ low dependence, $3-4=$ moderate, $5-6=$ high).
Alcohol use: The Alcohol Use Disorders Identification Test-Short form (AUDIT-C) was used to measure alcohol use. ${ }^{17}$ Scores of 4 or more for males (sensitivity $=0.95$, specificity 0.60$)^{17}$ and 3 or more for females (sensitivity: $\quad 0.66$ Specificity 0.94$)^{18}$ indicated risky drinking.

Financial stress was assessed using the financial stress scale ${ }^{19}$ which uses a yes/no response scale to assess participants' experience of financial stress in terms of eight items of financial or material deprivation, for example, "being unable to heat home". Scores on this scale range from 0 to 8 , with higher values indicating higher levels of financial stress.

Depression and anxiety: The Patient Health Questionnaire-4 (PHQ4), an ultrabrief screening measure for anxiety and depression, was used. This is a composite measure of anxiety and depression within the past 2 weeks. Higher scores indicate higher likelihood of underlying depressive or anxiety disorder. ${ }^{20}$

Social contact was measured by using two questions, "How often are you in contact with any member of your family-including visits, phone calls, letters, or emails?" and "How often are you in contact with any friendsincluding visits, phone calls, letters, or emails?." Response options were (A) "Nearly every day" (B) " 34 days per week" (C) "1-2 days per week" (D) "1-3 days per month" (E) "Less than once a month" (F) "Never" (G) "No family/friends". ${ }^{21}$

Resilience was measured using the Brief Resilience Scale (BRS). ${ }^{22}$ The BRS comprises 6 items and conceptualises resilience as an individual's way of "bouncing back" after adversity.

Sociodemographic variables: Participants self-reported their age, gender, highest level of education, marital status, weekly net income level, type of housing, and Aboriginal or Torres Strait Islander status.

\section{Analyses}

Sample size and power calculations for the CiQ trial are available elsewhere. ${ }^{6}$ SAS V.9.3 (SAS Institute Inc., Cary, North Carolina, USA) was used for all analyses. ${ }^{23}$ Descriptive statistics of sociodemographic (age, gender, marital status, Aboriginal or Torres Strait Islander status, education, housing type, income, income source) and smoking (nicotine dependence, type of tobacco used, previous quit attempt, preference for abrupt or gradual cessation, quitting self-efficacy, enjoyment of smoking, smoker identity, friends or family who smoke, quit intentions, and motivation to quit), alcohol consumption, and mental health (depression, anxiety, resilience, social contact, financial stress) variables are presented as numbers and percentages for categorical variables and means (SD) or median (IQR) for continuous variables, depending on distribution of the data.

Comparison of characteristics between consenter and non-consenters was performed using the $\chi^{2}$ test for categorical variables, and independent $\mathrm{t}$ tests (parametric) 
or Mann-Whitney U tests (non-parametric) for continuous variables.

Logistic regression was used to examine factors associated with participant consent for the RCT. Variables included in the model were selected based on clinical and scientific knowledge prior to analysis of the data. Multivariate model selection was performed to create the final adjusted model; variables were removed if these had a $p$ value $>0.2$ and were not of clinical significance thus ensuring that the inclusion or removal of each variable did not grossly affect either the fit of the model (LRT or akaike information criterion (AIC)) or the estimates for remaining variables. Within the multivariable model, collinearity was checked using variance inflation factors and linearity assumption for continuous variables, and the logit of the outcome were examined. Crude and adjusted ORs with $95 \%$ CIs and Wald $\chi^{2}$ test $p$ values will be presented for variables in the final model.

\section{RESULTS}

\section{Sample}

Of the 906 participants who completed the baseline questionnaire, 896 were screened for eligibility for the smoking cessation trial; 584 (65\%) were current smokers and were invited to participate in the trial, of whom $431(74 \%)$ consented and $153(26 \%)$ declined to participate. Table 1 shows the sociodemographic characteristics, table 2 shows the psychosocial variables and table 3 summarises the smoking-related characteristics of those who did or did not consent to participate in the CiQ trial.

\section{Comparison of trial participants and non-participants}

Participants and non-participants did not differ according to sociodemographic (age, gender, education, income amount and source, marital status, Indigenous status and housing type) or psychosocial variables (contact with family and friends, depression, anxiety, resilience and financial stress). A number of smoking-related variables were significantly associated with consenting to the intervention trial (see table 3).

Results from the adjusted logistic regression model (see table 4) showed a number of factors made independent contributions to the OR of consenting to participate in the trial. The OR of participation were twice as high for those reporting 'high' motivation to quit compared to the 'moderate' motivation group, and five times higher than the 'low' motivation group $(p=0.0007)$. The ORs of consenting were also twice higher for those with a preference for gradual reduction in cigarettes in quit attempts compared with 'no preference' ( $\mathrm{OR}=2.1,95 \%$ CI 1 to 4.1). The ORs were lower for those reporting 'don't know' regarding their enjoyment of smoking compared

Table 1 Sociodemographic characteristics of smoking cessation trial participants and non-participants $(n=584)$

\begin{tabular}{|c|c|c|c|c|}
\hline & \multicolumn{3}{|c|}{ Participation n (\%) } & \multirow[b]{2}{*}{ p Value* } \\
\hline & Yes & No & Total & \\
\hline \multicolumn{5}{|l|}{ Age } \\
\hline Mean $(S D)$ years & $38(11)$ & $39(10)$ & $77(11)$ & 0.29 \\
\hline \multicolumn{5}{|l|}{ Gender } \\
\hline Female & $210(49)$ & $81(47)$ & $291(50)$ & 0.37 \\
\hline Male & $221(51)$ & $72(53)$ & $293(50)$ & \\
\hline \multicolumn{5}{|l|}{ Education } \\
\hline Up to primary school & 82 (19) & $33(22)$ & $115(20)$ & \\
\hline Secondary school & $237(55)$ & $91(59)$ & $328(56)$ & \\
\hline Tertiary qualifications & $112(26)$ & 29 (19) & $141(24)$ & 0.21 \\
\hline \multicolumn{5}{|l|}{ Marital status } \\
\hline Married or living with partner & $53(12)$ & $22(14)$ & $75(13)$ & \\
\hline Separated/divorced/widowed & $143(33)$ & $52(34)$ & $195(34)$ & \\
\hline Never married & $235(55)$ & $79(52)$ & $314(54)$ & 0.81 \\
\hline \multicolumn{5}{|l|}{ Housing type } \\
\hline Own house & $13(3)$ & $5(3)$ & $18(3)$ & \\
\hline Rental house & $128(30)$ & $44(29)$ & $172(29)$ & \\
\hline No home/hotel, motel, with family or friends, street living, other & $84(19)$ & $22(14)$ & $106(18)$ & \\
\hline Government housing or supported accommodation & $206(48)$ & $82(54)$ & $288(49)$ & 0.65 \\
\hline \multicolumn{5}{|l|}{ Income amount } \\
\hline$<\$ 200$ per week & $115(28)$ & $42(28)$ & $157(28)$ & \\
\hline$\$ 201-\$ 400$ per week & $234(58)$ & $77(51)$ & $311(56)$ & \\
\hline$>\$ 400$ per week & $55(14)$ & $31(21)$ & $86(16)$ & 0.11 \\
\hline \multicolumn{5}{|l|}{ Income source } \\
\hline Paid employment (full or part time) or other (eg, friends or family) & $25(6)$ & $8(6)$ & $33(6)$ & \\
\hline Government benefits & $406(94)$ & $145(26)$ & $551(94)$ & 0.28 \\
\hline Aboriginal or Torres Strait Islander & $74(17)$ & $17(11)$ & $91(16)$ & 0.08 \\
\hline
\end{tabular}


Table 2 Alcohol use and psychosocial characteristics of smoking cessation trial participants and non-participants $(n=584)$

\begin{tabular}{|c|c|c|c|c|}
\hline & \multicolumn{3}{|c|}{ Participation n (\%) } & \multirow[b]{2}{*}{ p Value* } \\
\hline & Yes & No & Total & \\
\hline \multicolumn{5}{|l|}{ Alcohol use } \\
\hline No use & $108(25)$ & $40(26)$ & $148(26)$ & \\
\hline Non-risky use & $65(15)$ & $22(14)$ & $87(15)$ & \\
\hline Risky use & $252(59)$ & $90(59)$ & $342(59)$ & 0.96 \\
\hline \multicolumn{5}{|l|}{ Contact with family } \\
\hline Never or no family & $68(16)$ & $22(14)$ & $90(15)$ & \\
\hline 1-3 days a month/less than once a month & $118(27)$ & $40(26)$ & $158(27)$ & \\
\hline $1-2$ days a week & $90(21)$ & $25(16)$ & $115(20)$ & \\
\hline Nearly every day/3-4 days a week & $155(36)$ & $66(43)$ & $221(38)$ & 0.40 \\
\hline \multicolumn{5}{|l|}{ Contact with friends } \\
\hline Never or no friends & $75(17)$ & $23(15)$ & $98(17)$ & \\
\hline $1-3$ days a month/less than once a month & $88(20)$ & 27 (18) & $115(20)$ & \\
\hline $1-2$ days a week & $86(20)$ & $31(20)$ & $117(20)$ & \\
\hline Nearly every day/3-4 days a week & $182(42)$ & $72(47)$ & $254(43)$ & 0.71 \\
\hline \multicolumn{5}{|l|}{ Financial stress score } \\
\hline Mean (SD) & $5.7(1.7)$ & $5.8(1.7)$ & $5.7(1.7)$ & 0.35 \\
\hline \multicolumn{5}{|l|}{ Depression } \\
\hline Median (minimum, maximum) & $12(0.27)$ & $11(0.27)$ & $12(0.27)$ & 0.99 \\
\hline \multicolumn{5}{|l|}{ Anxiety } \\
\hline Median (minimum, maximum) & $3(0.6)$ & $4(0.6)$ & $3(0.6)$ & 0.93 \\
\hline \multicolumn{5}{|l|}{ Resilience } \\
\hline Median (minimum, maximum) & $2.8(1.5)$ & $3(1.5)$ & $3(1.5)$ & 0.11 \\
\hline
\end{tabular}

to 'not at all' enjoying smoking ( $\mathrm{OR}=0.3,95 \%$ CI 0.9 to $0.8)$, and reporting that 'about half' $(\mathrm{OR}=0.5 ; 95 \% \mathrm{CI} 0.3$ to 0.9 ) or 'a few/less than half' ( $\mathrm{OR}=0.6$; $95 \%$ CI 0.3 to 1)) of their friends or family smoked lowered the OR of participating than reporting that 'most or all' of their family or friends smoked.

\section{DISCUSSION}

This study is the first study to examine the characteristics that distinguish socially disadvantaged smokers who consent to participate in a smoking cessation trial from those who do not. A large range of personal characteristics were examined and a number of these differentiated the participants in the trial from non-participants. Lower enjoyment of smoking, higher motivation to quit smoking, preference for gradual reduction approach for cessation, and high numbers of family and friends who smoke were associated with consent into a smoking cessation trial for a sample of socially disadvantaged smokers.

The extent of socioeconomic disadvantage experienced by the sample is worth noting. The sample consisted of adults with high rates of homelessness, anxiety and depression, alcohol abuse, self-identification as Aboriginal or Torres Strait Islander peoples and low education attainment. The sample displayed exceptionally low income with $84 \%$ reporting income well below the Australian single-person 'poverty line' of $\$ 500$ per week, ${ }^{24}$ and $94 \%$ dependent on government benefits as their main source of income. The high consent rate
(74\%) from those eligible to enter the trial may be due to interest in seeking assistance to quit smoking, that is, the offer, made during recruitment, of free NRT if randomised to the intervention group, as well as financial reimbursements for their time. Notwithstanding the socioeconomic disadvantage of the clients in the sample, these incentives may be particularly attractive to individuals under financial strain. ${ }^{25}$

It is important to identify those factors which might motivate socially disadvantaged smokers to participate in smoking cessation trials. Some factors associated with intrinsic motivation to quit were found to differentiate participants from non-participants. Enjoyment of smoking was found to be associated with participation whereby those who reported ambivalence or uncertainty regarding their enjoyment of smoking had lower odds of participation relative to those reporting not enjoying smoking. As expected, higher rating of motivation to stop smoking was associated with greater odds of participation in the cessation trial. There is a need to increase interest in participating in smoking cessation research among smokers who may not be motivated to quit smoking. ${ }^{13}$ Use of motivational interviewing techniques during recruitment warrants further consideration. There were also greater odds of participation in the trial for those preferring an approach to quitting that allowed a gradual reduction in smoking, relative to no preference. Reduce to quit approaches have been found to be effective for cessation. ${ }^{26}$ There may be a need to offer a 'reduce to quit' approach which is likely to attract smokers from 
Table 3 Smoking-related characteristics of smoking cessation trial participants and non-participants $(n=584)$

\begin{tabular}{|c|c|c|c|c|}
\hline & \multicolumn{3}{|c|}{ Participation n (\%) } & \multirow[b]{2}{*}{ p Value ${ }^{\star}$} \\
\hline & Yes & No & Total & \\
\hline \multicolumn{5}{|l|}{ Age started smoking } \\
\hline Mean (SD) years & $15(4)$ & $15(5)$ & $15(4)$ & 0.57 \\
\hline \multicolumn{5}{|l|}{ Nicotine dependence (HSI) } \\
\hline Low & $130(34)$ & $42(32)$ & $172(33)$ & \\
\hline Moderate & $194(51)$ & $68(52)$ & $262(51)$ & \\
\hline High & $60(16)$ & $21(16)$ & $81(16)$ & 0.93 \\
\hline \multicolumn{5}{|l|}{ Tobacco type smoked } \\
\hline Pre-rolled cigarettes & $249(58)$ & $85(56)$ & $334(57)$ & \\
\hline Roll your own cigarettes & $173(40)$ & $65(42)$ & $238(41)$ & \\
\hline Chop chop (low grade loose leaf) & $9(2)$ & $3(2)$ & $12(2)$ & 0.88 \\
\hline \multicolumn{5}{|l|}{ Smoker identity } \\
\hline I hate being a smoker & $149(35)$ & $44(29)$ & $193(33)$ & \\
\hline I am unhappy about being a smoker & $176(41)$ & $62(41)$ & $238(41)$ & \\
\hline I am happy about being a smoker & $26(6)$ & $12(8)$ & $38(7)$ & \\
\hline Do not know & 80 (19) & $35(23)$ & $115(20)$ & 0.43 \\
\hline \multicolumn{5}{|l|}{ Enjoyment of smoking } \\
\hline Not at all & $54(13)$ & $9(6)$ & $63(11)$ & \\
\hline Not particularly & $141(33)$ & $53(35)$ & $194(33)$ & \\
\hline Quite a bit & $138(32)$ & $38(25)$ & $176(30)$ & \\
\hline Very much & 57 (14) & $32(21)$ & 89 (15) & \\
\hline Do not know & $40(9)$ & $21(14)$ & $61(10)$ & 0.01 \\
\hline \multicolumn{5}{|l|}{ Friends or family who smoke } \\
\hline None & $35(8)$ & $14(9)$ & $49(8)$ & \\
\hline A few or less than half & $122(28)$ & $52(34)$ & $174(30)$ & \\
\hline About half & $104(24)$ & $42(27)$ & $146(25)$ & \\
\hline Most or all of them & $170(39)$ & $45(29)$ & $215(37)$ & 0.18 \\
\hline \multicolumn{5}{|l|}{ Quit attempts ever } \\
\hline Yes & $362(84)$ & $125(82)$ & $487(83)$ & 0.51 \\
\hline \multicolumn{5}{|l|}{ Quit attempt approach preference } \\
\hline Stop smoking suddenly & $131(30)$ & $57(37)$ & $188(32)$ & \\
\hline Gradual reduction of cigarettes & $261(61)$ & $74(48)$ & $335(58)$ & \\
\hline No preference & $39(9)$ & $22(14)$ & $61(10)$ & 0.02 \\
\hline \multicolumn{5}{|l|}{ Quit self-efficacy } \\
\hline Not at all sure & $138(32)$ & $52(34)$ & $190(33)$ & \\
\hline Slightly sure & $87(20)$ & $27(18)$ & $114(20)$ & \\
\hline Moderately sure & $110(26)$ & $40(26)$ & $150(26)$ & \\
\hline Very sure & $52(12)$ & $22(14)$ & 74 (13) & \\
\hline Extremely sure & $44(10)$ & $12(8)$ & $56(10)$ & 0.80 \\
\hline \multicolumn{5}{|l|}{ Quit intention } \\
\hline Quit in the next 30 days & $83(19)$ & $15(10)$ & $98(17)$ & \\
\hline Quit in the next 6 months & $121(28)$ & $44(29)$ & $165(28)$ & \\
\hline Quit, but not in next 6 months & $60(14)$ & $18(12)$ & 78 (13) & \\
\hline Never want to quit & $14(3)$ & $10(7)$ & $24(4)$ & \\
\hline Do not know & $153(35)$ & $66(43)$ & 219 (38) & 0.03 \\
\hline \multicolumn{5}{|l|}{ Motivation to quit } \\
\hline High & $162(38)$ & $37(24)$ & $199(34)$ & \\
\hline Moderate & $181(42)$ & $65(43)$ & $244(42)$ & \\
\hline Low & $85(20)$ & $50(33)$ & $135(23)$ & $<0.001$ \\
\hline
\end{tabular}

socially disadvantaged groups to cessation trials. Having higher numbers of family and friends who smoke was a surprising association with consent to participate. Socially disadvantaged smokers report low social support to quit smoking and being embedded in a social network and context of smoking. ${ }^{27}$ Perhaps for these smokers, the offer of possibly receiving a smoking cessation programme was an opportunity to gain some assistance in their attempts to quit smoking.

The current results may also aid stop smoking services develop strategies for attracting socially disadvantaged smokers. Some studies have examined the characteristics 
Table 4 Logistic regression models of participant factors* associated with participation in the smoking cessation trial $(n=584)$

\begin{tabular}{|c|c|c|c|c|c|}
\hline & & $\begin{array}{l}\text { Unadjusted } \\
\text { OR }(95 \% \mathrm{Cl})\end{array}$ & p Value & $\begin{array}{l}\text { Adjusted } \\
\text { OR (95\% Cl) }\end{array}$ & p Value \\
\hline Age in years (continuous) & & $0.99(0.9$ to 1.0$)$ & 0.29 & 0.99 (0.9 to 1.0$)$ & 0.29 \\
\hline \multicolumn{6}{|l|}{ Gender } \\
\hline Male & Ref & - & & - & \\
\hline Female & & 0.85 (0.6 to 1.2$)$ & 0.37 & $0.63(0.4$ to 1.0$)$ & 0.05 \\
\hline \multicolumn{6}{|l|}{ Indigenous status } \\
\hline Non-Aboriginal & Ref & - & & & \\
\hline Aboriginal or Torres Strait Islander & & 1.66 (0.9 to 2.9$)$ & 0.07 & 2.05 (1.0 to 4.1$)$ & 0.05 \\
\hline Income & & & 0.11 & & 0.08 \\
\hline$>\$ 400$ per week & Ref & - & & - & \\
\hline$\$ 201-\$ 400$ per week & & $1.71(1.0$ to 2.0$)$ & & $1.94(1.0$ to 4.0$)$ & \\
\hline$<\$ 200$ per week & & $1.54(0.9$ to 2.7$)$ & & $1.43(0.7$ to 3$)$ & \\
\hline Anxiety score (continuous) & & $0.99(0.9$ to 1.1$)$ & 0.86 & $0.96(0.8$ to 1.1$)$ & 0.59 \\
\hline Depression score (continuous) & & $1.0(0.9$ to 1.0$)$ & 0.99 & $0.99(0.9$ to 1.0$)$ & 0.73 \\
\hline Financial stress score (continuous) & & $0.96(0.9$ to 1.1$)$ & 0.41 & $0.89(0.8$ to 1.0$)$ & 0.11 \\
\hline Resilience score (continuous) & & $0.82(0.6$ to 1.1$)$ & 0.10 & $0.77(0.6$ to 1.0$)$ & 0.11 \\
\hline Heaviness of smoking index & & & 0.93 & & 0.63 \\
\hline Low & Ref & - & & - & \\
\hline Moderate & & $0.92(0.6$ to 1.4$)$ & & 0.78 (0.5 to 1.3$)$ & \\
\hline High & & $0.92(0.4$ to 1.7$)$ & & $0.86(0.4$ to 1.8$)$ & \\
\hline Enjoyment of smoking & & & 0.01 & & 0.02 \\
\hline Not at all & Ref & - & & - & \\
\hline Not particularly & & $0.44(0.2$ to 0.9$)$ & & 0.44 (0.2 to 1.2$)$ & \\
\hline Quite a bit & & 0.61 (0.3 to 1.3$)$ & & 0.79 (0.3 to 2.2$)$ & \\
\hline Very much & & $0.30(0.1$ to 0.7$)$ & & $0.42(0.1$ to 1.3$)$ & \\
\hline Do not know & & $0.32(0.1$ to 0.8$)$ & & $0.27(0.1$ to 0.8$)$ & \\
\hline Friends or family who smoke & & & 0.17 & & 0.12 \\
\hline Most or all of them & Ref & - & & - & \\
\hline About half & & $0.66(0.4$ to 1.1$)$ & & $0.54(0.3$ to 0.9$)$ & \\
\hline A few/less than half & & $0.62(0.4$ to 0.9$)$ & & $0.56(0.3$ to 1.0$)$ & \\
\hline None & & 0.66 (0.3 to 1.3$)$ & & $0.87(0.4$ to 2.1$)$ & \\
\hline \multicolumn{6}{|l|}{ Quit attempt ever } \\
\hline Yes & Ref & - & & - & \\
\hline No & & 0.85 (0.5 to 1.4$)$ & 0.51 & $1.06(0.6$ to 1.9$)$ & 0.85 \\
\hline Quit self-efficacy & & & 0.79 & & 0.59 \\
\hline Not at all sure & Ref & - & & - & \\
\hline Slightly sure & & $1.21(0.7$ to 2.1$)$ & & $0.79(0.4$ to 1.5$)$ & \\
\hline Moderately sure & & $1.04(0.6$ to 1.7$)$ & & 0.79 (0.4 to 1.5$)$ & \\
\hline Very sure & & $0.89(0.5$ to 1.6$)$ & & $0.51(0.2$ to 1.1$)$ & \\
\hline Extremely sure & & $1.38(0.7$ to 2.8$)$ & & $0.79(0.3$ to 2.0$)$ & \\
\hline Quit attempt approach preference & & & 0.02 & & 0.08 \\
\hline No preference & Ref & - & & - & \\
\hline Gradual reduction of cigarettes & & 1.99 (1.1 to 3.6$)$ & & 2.07 (1.0 to 4.2$)$ & \\
\hline Stop smoking suddenly & & $1.29(0.7$ to 2.4$)$ & & $1.43(0.7$ to 3.0$)$ & \\
\hline Motivation to quit & & & $<0.01$ & & $<0.01$ \\
\hline High & Ref & - & & - & \\
\hline Moderate & & $0.62(0.4$ to 1.0$)$ & & 0.50 (0.3 to 0.9$)$ & \\
\hline Low & & $0.39(0.2$ to 0.6$)$ & & $0.26(0.1$ to 0.5$)$ & \\
\hline Alcohol use & & & 0.95 & & 0.81 \\
\hline No use & Ref & - & & - & \\
\hline Non-risky use & & $1.09(0.6$ to 2.0$)$ & & $1.11(0.5$ to 2.3$)$ & \\
\hline Risky use & & $1.04(0.7$ to 1.6$)$ & & $1.19(0.7$ to 2.0$)$ & \\
\hline
\end{tabular}

of smokers attending smoking cessation clinics. $^{28} 29$ Using largely observational data, these studies have found that the UK-based stop smoking services have been successful at attracting smokers from socioeconomically disadvantaged areas $^{28}$ and that this has translated into increased abstinence rates for 1 year. 


\section{Study limitations}

There are a number of study limitations which should be considered. The two-stage recruitment process, while useful in providing depth and breadth of information about trial participants and non-participants, excluded eligible individuals who were not interested or did not consent to the initial health survey. There is low probability of systematic biases during recruitment given that the consent rate in the health survey was high (96\%) among those who did approach the RA, and attempts were made to ensure that at this stage no reference to the smoking cessation trial was made by describing the survey as a 'general health survey', ensuring that smokers were just as likely as non-smokers to participate. However, we do not know how many clients were not referred to the RA and did not approach the RA. Although staff was asked to refer all eligible clients to the RA, there is the possibility that some were missed or that some clients did not approach the RA. A further study limitation is that external factors not explored in this study, such as lack of time, a high crisis situation for visiting the SCSO and low literacy levels, may also contribute to non-participation.

In conclusion, based on current results, it would appear important that smoking cessation trials that aim to recruit socially disadvantaged smokers incorporate recruitment strategies that provide extrinsic and intrinsic motivational techniques such as financial reimbursements; use of known and acceptable settings, for example, the SCSO services; intervention components, including NRT at no cost; offers of 'reduce to quit' strategies; and motivational interviewing components. Given the increasing urgency for conducting methodologically sound smoking cessation trials for smokers from socially disadvantaged groups, the results of this study are pertinent.

\section{Author affiliations \\ ${ }^{1}$ Faculty of Health and Medicine, Centre for Translational Neuroscience and Mental Health, School of Medicine and Public Health, University of Newcastle, Callaghan, New South Wales, Australia \\ ${ }^{2}$ Priority Research Centre for Health Behaviour, University of Newcastle \& Hunter Medical Research Institute, New Lambton, New South Wales, Australia ${ }^{3}$ National Centre for Epidemiology and Population Health, Australian National University, Canberra, Australian Capital Territory, Australia \\ ${ }^{4}$ Department of Epidemiology and Public Health, Health Behaviour Research Centre, University College London, London, UK \\ ${ }^{5}$ Department of Health Promotion, Social and Behavioral Health, College of Public Health, University of Nebraska Medical Center, Omaha, Nebraska, USA ${ }^{6}$ Hunter Medical Research Institute, Newcastle, New South Wales, Australia}

Acknowledgements The authors would like to thank Leah Zoszak, Emma Walter and Gamze Abramov for their assistance in data collection. The authors would also like to thank the participating community service organisations and their clients for taking part in the research.

Contributors $\mathrm{BB}, \mathrm{CP}, \mathrm{JB}$ and $\mathrm{LT}$ conceived of the design of the current study. $\mathrm{KP}$ conducted data analysis with input from $\mathrm{CO}$ and $\mathrm{CD}$. BB, CP, JB, $\mathrm{LT}, \mathrm{CD}$, $R W, C O, K P$, and $A G$ aided in interpretation of the results. $B B, C P, J B, L T, C D$, $\mathrm{RW}, \mathrm{CO}, \mathrm{KP}$, and $\mathrm{AG}$ contributed to critical revision of the paper. $\mathrm{BB}, \mathrm{CP}, \mathrm{JB}$, $L T, C D, R W, C O, K P$, and $A G$ approved the final version for submission. $B B$, $\mathrm{CP}, \mathrm{JB}, \mathrm{LT}, \mathrm{CD}, \mathrm{RW}, \mathrm{CO}, \mathrm{KP}$, and $\mathrm{AG}$ have read and met the ICMJE criteria for authorship.
Funding This work was supported by a grant from the National Health and Medical Research Council (NHMRC) of Australia (grant number 631055). LT is supported by a 50:50 Scholarship from University of Newcastle and Cancer Council NSW. BB is supported by a Cancer Institute NSW Career Development Fellowship. JB is supported by an Australian Research Council Post-Doctoral Industry Fellowship. CP and JB are supported by Newcastle Cancer Control Collaborative funding.

Competing interests $\mathrm{LT}, \mathrm{BB}, \mathrm{CP}, \mathrm{JB}, \mathrm{MS}, \mathrm{CD}, \mathrm{CO}, \mathrm{AG}$ and $\mathrm{KP}$ have no competing interests to declare. RW undertakes research and consultancy for companies that develop and manufacture smoking cessation medications. He is an honorary co-director of UK's National Centre for Smoking Cessation and Training, and a trustee of the charity, QUIT. His salary is funded by Cancer Research UK. He is a member of the UK Centre for Tobacco and Alcohol Studies. MS is funded through the National Institutes of Health.

Ethics approval University of Newcastle Human Research Ethics Committee.

Provenance and peer review Not commissioned; externally peer reviewed.

Data sharing statement No additional data are available.

Open Access This is an Open Access article distributed in accordance with the Creative Commons Attribution Non Commercial (CC BY-NC 4.0) license, which permits others to distribute, remix, adapt, build upon this work noncommercially, and license their derivative works on different terms, provided the original work is properly cited and the use is non-commercial. See: http:// creativecommons.org/licenses/by-nc/4.0/

\section{REFERENCES}

1. Baker A, Ivers RG, Bowman J, et al. Where there's smoke, there's fire: high prevalence of smoking among some sub-populations and recommendations for intervention. Drug Alcohol Rev 2006;25:85-96.

2. Glover JD, Hetzel DM, Tennant SK. The socioeconomic gradient and chronic illness and associated risk factors in Australia. Aust New Zealand Health Policy 2004;1:8.

3. Bonevski B, Randell M, Paul C, et al. Reaching the hard-to-reach: a systematic review of strategies for improving health and medical research with socially disadvantaged groups. BMC Med Res Methodol 2014;14:42

4. Graham AL, Papandonatos GD, DePue JD, et al. Lifetime characteristics of participants and non-participants in a smoking cessation trial: implications for external validity and public health impact. Ann Behav Med 2008;35:295-307.

5. Warner C, Sewali B, Olayinka A, et al. Smoking cessation in homeless populations: who participates and who does not. Nicotine Tob Res 2014;16:369-72.

6. Bonevski B, Paul C, D'Este C, et al. RCT of a client-centred, caseworker-delivered smoking cessation intervention for a socially disadvantaged population. BMC Public Health 2011;11:70.

7. Bryant J, Bonevski B, Paul C. A survey of smoking prevalence and interest in quitting among social and community service organisation clients in Australia: a unique opportunity for reaching the disadvantaged. BMC Public Health 2011;11:827.

8. Caldwell $\mathrm{PH}$, Hamilton $\mathrm{S}$, Tan $\mathrm{A}$, et al. Strategies for increasing recruitment to randomised controlled trials: systematic review. PLoS Med 2010;7:e1000368.

9. Bryant J, Bonevski B, Paul C, et al. Delivering smoking cessation support to disadvantaged groups: a qualitative study of the potential of community welfare organizations. Health Educ Res 2010;25:979-90.

10. Digivey Survey Suite [computer program]. Arizona, USA. 3.1.36.0.

11. Fidler J, Shahab L, West O, et al. 'The smoking toolkit study': a national study of smoking and smoking cessation in England. BMC Public Health 2011;11:479.

12. Siahpush $\mathrm{M}$, Yong $\mathrm{HH}$, Borland $\mathrm{R}$, et al. Socioeconomic position and abrupt versus gradual method of quitting smoking: findings from the International Tobacco Control Four-Country Survey. Nicotine Tob Res 2010;12(Suppl):S58-63.

13. Fidler J, West R. Enjoyment of smoking and urges to smoke as predictors of attempts and success of attempts to stop smoking: a longitudinal study. Drug Alcohol Depend 2011;115:30-4.

14. Tombor I, Shahab L, Brown J, et al. Positive smoker identity as a barrier to quitting smoking: Findings from a national survey of smokers in England. Drug Alcohol Depend 2013;133:740-5.

15. Zhou X, Nonnemaker J, Sherrill B, et al. Attempts to quit smoking and relapse: factors associated with success or failure from the ATTEMPT cohort study. Addict Behav 2009;34:365-73. 
16. Kozlowski LT, Porter CQ, Orleans CT, et al. Predicting smoking cessation with self-reported measures of nicotine dependence: FTQ, FTND, and HSI. Drug Alcohol Depend 1994;34: 211-16.

17. Bush K, Kivlahan DR, McDonell MB, et al. The AUDIT alcohol consumption questions (AUDIT-C): an effective brief screening test for problem drinking. Ambulatory Care Quality Improvement Project (ACQUIP). Alcohol Use Disorders Identification Test. Arch Intern Med 1998;158:1789-95.

18. Bradley KA, Bush KR, Epler AJ, et al. Two brief alcohol-screening tests From the Alcohol Use Disorders Identification Test (AUDIT): validation in a female Veterans Affairs patient population. Arch Intern Med 2003:163:821-9.

19. Siahpush M, Carlin JB. Financial stress, smoking cessation and relapse: results from a prospective study of an Australian national sample. Addiction 2006;101:121-7.

20. Kroenke K, Spitzer RL, Williams JB, et al. An ultra-brief screening scale for anxiety and depression: the PHQ-4. Psychosomatics 2009;50:613-21.

21. Australian Bureau of Statistics. National survey of mental health and wellbeing: summary of results. Australian Bureau of Statistics, 2007.
22. Smith BW, Dalen J, Wiggins K, et al. The brief resilience scale: assessing the ability to bounce back. Int J Behav Med 2008;15:194-200.

23. SAS Institute Inc. [computer program]. Cary, NC, USA.

24. Melbourne Institute of Applied and Social Research. Poverty lines Australia June quarter 2014. University of Melbourne, 2014.

25. Kendzor DE, Businelle MS, Poonawalla IB, et al. Financial incentives for abstinence among socioeconomically disadvantaged individuals in smoking cessation treatment. Am J Public Health 2015;105:1198-205.

26. Lindson-Hawley N, Aveyard P, Hughes JR. Reduction versus abrupt cessation in smokers who want to quit. Cochrane Database Syst Rev 2012;11:CD008033.

27. Paul CL, Ross S, Bryant J, et al. The social context of smoking: a qualitative study comparing smokers of high versus low socioeconomic position. BMC Public Health 2010;10:211.

28. Chesterman J, Judge K, Bauld L, et al. How effective are the English smoking treatment services in reaching disadvantaged smokers? Addiction 2005;100(Suppl 2):36-45.

29. Ferguson J, Bauld L, Chesterman J, et al. The English smoking treatment services: one-year outcomes. Addiction 2005; 100(Suppl 2):59-69. 